\title{
Deposição de nutrientes pela serapilheira em um fragmento de Floresta Estacional Decidual no Rio Grande do Sul
}

\author{
Joseane Savian Marafiga ${ }^{1}$, Márcio Viera², Denise Andréia Szymczak ${ }^{3}$,Mauro Valdir Schumacher ${ }^{4}$, Peter Trüby ${ }^{5}$
}

\section{RESUMO}

O conhecimento do aporte de nutrientes das espécies que compõem a Floresta Estacional Decidual é ainda incipiente. Objetivou-se, neste trabalho, determinar a deposição de nutrientes pela serapilheira de diferentes espécies, em uma Floresta Estacional Decidual, no município de Itaara, RS. Para a coleta de serapilheira, foram demarcadas seis parcelas de 25,0 m x 17,0 m cada, sendo distribuídos cinco coletores em cada parcela. As coletas de serapilheira foram realizadas mensalmente, no período de janeiro de 2006 a dezembro de 2007. A serapilheira foi separada em folhas, galhos finos (diâmetro $<0,5 \mathrm{~cm}$ ) e miscelânea (flores, frutos, sementes e restos vegetais não identificáveis). As folhas foram separadas de acordo com as espécies mais representativas da floresta. O material foi analisado quanto aos teores de macro e micronutrientes. A concentração de nutrientes diferiu entre as espécies. A maior transferência de nutrientes ocorreu por meio da fração folhas, seguido pelos galhos finos e miscelânea. Dentre as espécies avaliadas, a espécie Parapiptadenia rigida apresentou a maior transferência de nutrientes, com exceção do Mn, o qual foi mais transferido pela espécie Matayba elaeagnoides, juntamente com a espécie Ocotea pulchella.

Palavras-chave: floresta nativa, mata atlântica, nutrição florestal, produção de serapilheira

\section{ABSTRACT}

\section{Nutrients input from litter in a seasonal deciduous forest fragment in Rio Grande do Sul}

Knowledge on nutrient deposition from species that compose the Deciduous Forest is incipient. The objective of this study was to determine the nutrient input by different species, from litter deposition in a Seasonal Deciduous Forest in Itaara, RS. Six plots $(25.0 \mathrm{~m}$ x $17.0 \mathrm{~m})$ were installed for litter collection,. In each plot, 5 mesh-screen traps were allocated. The litter was monthly collected from January 2006 to December 2007. Litter was sorted out in leaves, twigs (diameter $<0.5 \mathrm{~cm}$ ) and mixture (flowers, fruits, seeds and non identified plant parts). Leaves were separated regarding the most representative species in the forest. The material was analyzed for the levels of macro and micronutrients. The concentration of nutrients differed between species. The highest nutrient input occurred from the leaf fraction, followed by twigs and mixture. Among the evaluated species, Parapiptadenia rigida showed the highest nutrient transfer, except for Mn that was highest in Matayba elaeagnoides, and Ocotea pulchella.

Key words: native forest, Atlantic forest, forest nutrition, litterfall.

\footnotetext{
Recebido para publicação em 10/12/2010 e aprovado em 13/11/2012.

${ }^{1}$ Engenheira Florestal. Departamento de Ciências Florestais, Universidade Federal de Santa Maria, Avenida Roraima, 1000, Caixa Postal 5096, 97105-900, Santa Maria, Rio Grande do Sul, Brasil. josemarafiga@yahoo.com.br

${ }^{2}$ Engenheiro Florestal, Doutor. Departamento Multidisciplinar da Universidade Federal de Santa Maria - Campus Silveira Martins - Rua Francisco Guerino n.407, Centro - 97195000 - Silveira Martins-RS; e-mail: vieraflorestal@yahoo.com.br (autor para correspondência).

${ }_{3}^{3}$ Engenheira Florestal. Mestranda do Programa de Pós-graduação em Engenharia Florestal da Universidade Federal de Santa Maria, Avenida Roraima, 1000, Caixa Postal 5096, 97105-900, Santa Maria, Rio Grande do Sul, Brasil. deniseximi@yahoo.com.br

${ }^{4}$ Engenheiro Florestal, Doutor. Departamento de Ciências Florestais, Universidade Federal de Santa Maria, Avenida Roraima, 1000, Caixa Postal 5096, 97105-900, Santa Maria, Rio Grande do Sul, Brasil. Bolsista do CNPq. mvschumacher@gmail.com

${ }^{5}$ Engenheiro Florestal, Doutor. Institut für Bodenkunde und Waldernährungslehre, Albert-Ludwigs-Universität, Freiburg, Baden-Württemberg, Alemanha. peter.trueby@ bodenkunde.uni-freiburg.de
} 


\section{INTRODUÇÃO}

As áreas com florestas naturais, no Estado do Rio Grande do Sul, encontram-se em avançado processo de alteração de sua forma original e primitiva. Segundo Longhi et al. (1999), a devastação da floresta, em grande parte, foi causada por exploração intensiva de espécies de interesse madeireiro, a qual, com o posterior avanço das fronteiras agrícolas e, consequentemente, a derrubada das florestas, reduziu os maciços florestais a florestas fragmentadas, comprometendo a diversidade biológica e a conservação desses locais.

No sul do Brasil podem ser distinguidas três regiões florestais distintas: a Floresta Ombrófila Densa (mata atlântica), Floresta Ombrófila Mista (mata de Araucária) e a Floresta Estacional (mata latifoliada da bacia hidrográfica Paraná-Uruguai) (Klein, 1983). A Floresta Estacional, conforme sua fisionomia pode ser classificada como Semidecidual ou Decidual, dependendo da percentagem de árvores caducifólias que a compõem. Assim, quando aproximadamente de 20 a 50\% das árvores do estrato superior perdem as folhas, a floresta é classificada como Floresta Estacional Semidecidual e quando há perda por mais de 50\% das árvores desse estrato, a floresta é denominada Floresta Estacional Decidual (Klein, 1983). A Floresta Estacional Decidual, em seus estágios iniciais, médios e avançados de sucessão, ocupa 4,16\% da superfície do Estado do Rio Grande do Sul e 23,84\% da área total coberta com florestas naturais (Secretaria Estadual do Meio Ambiente, 2002).

A ciclagem de nutrientes, por meio da produção de serapilheira em florestas nativas, é um dos aspectos primordiais a serem estudados, com vistas ao planejamento do uso de espécies nativas para recuperação de ambientes alterados pela exploração indiscriminada (Poggiani \& Schumacher, 2004) e para o conhecimento da estrutura e do funcionamento dessas florestas (Viera et al., 2010). O conteúdo de nutrientes que são transferidos ao solo pela floresta pode interferir na capacidade produtiva e, também, no potencial de recuperação ambiental, pois os nutrientes resultantes do material orgânico depositado provocam modificações nas características químicas e físicas do solo (Vitousek \& Sanford, 1986; Viera \& Schumacher, 2010). Por meio da ciclagem de nutrientes, obtêm-se informações sobre a distribuição de nutrientes no ecossistema, podendo-se inferir sobre os fluxos entre os diferentes compartimentos (Golley, 1983; Jordan, 1985; Viera et al., 2010; Vital et al., 2004).

A concentração e o conteúdo de nutrientes na serapilheira variam em função do tipo de solo; da vegetação; da densidade arbórea; da habilidade da espécie em absorver, utilizar e translocar os nutrientes, antes da senescência foliar; da proporção de folhas, em relação aos demais componentes; do habitat natural (condições edafoclimáticas) e da idade das árvores (Vitousek \& Sanford, 1986; Koehler et al., 1987; Neves et al., 2001).

O estudo da ciclagem de nutrientes por espécies fornece informações básicas do processo de disponibilização de nutrientes, pelas espécies predominantes nos ecossistemas florestais, podendo, desta forma, revelar o potencial de espécies com maior adaptabilidade às condições específicas do ambiente, viáveis para inclusão em programas de recuperação de áreas degradadas (Herrera et al., 1981). Cada espécie, ou grupo de espécies, possui padrões específicos de deposição de serapilheira e nutrientes em ecossistemas naturais. Este trabalho teve por objetivo avaliar e indicar as principais espécies que devolvem nutrientes ao solo, por via de deposição de serapilheira, em uma Floresta Estacional Decidual, no município de Itaara, $\mathrm{RS}$.

\section{MATERIAL E MÉTODOS}

\section{Caracterização da área de estudo}

Este estudo foi desenvolvido em área pertencente ao Batalhão da Brigada Militar do Rio Grande do Sul, no Centro de Estudos e Treinamento, Reprodução Animal e Proteção Ambiental (CETRAPA), localizado no município de Itaara, na região central do Estado do Rio Grande do Sul. O local situa-se nas coordenada geográficas de $29^{\circ} 30^{\prime}$ de latitude Sul e $53^{\circ} 46^{\prime}$ de longitude Oeste, com altitude média de 400 m, em relação ao nível do mar.

A região possui clima tipo temperado úmido, com variedade climática $\mathrm{Cfa}$, segundo a classificação de Köppen, caracterizada pela ocorrência de chuvas durante todos os meses do ano, com temperatura do mês mais quente superior a $22^{\circ} \mathrm{C}$ e a do mês mais frio inferior a $3{ }^{\circ} \mathrm{C}$, com precipitação variando entre 1.700 e $1.800 \mathrm{~mm}$ anuais (Moreno, 1961). O solo do local é do tipo Neossolo Litólico eutrófico típico, com textura média, relevo forte ondulado e substrato basáltico, apresentando uma sequência de horizontes A/ $\mathrm{R}$ (Streck et al., 2008). As características químicas desse solo podem ser observadas na Tabela 1 .

Na floresta em estudo, Longhi \& Greff (2006) encontraram com maior frequência as espécies arbóreas: Allophylus edulis (A. St.-Hil., A. Juss \& Cambess.) Hieron. ex Niederl., Caliandra tweedii Benth., Cupania vernalis Cambess., Dalbergia frutescens (Vell.) Britton, Eugenia hyemalis Cambess., Helietta apiculata Benth., Lithraea brasiliensis Marchand, Lithraea molleoides (Vell.) Engl., Luehea divaricata Mart. \& Zucc., Matayba elaeagnoides Radlk., Nectandra megapotamica (Spreng.) Mez, Ocotea puberula (Rich.) Ness, Ocotea pulchella (Nees \& Mart.) Mez, Parapiptadenia rigida (Benth.) Brenan, Cordia americana (L.) Gottschling \& J.S.Mill., Quillaja brasiliensis (A. St.-Hil. \& Tul.) Mart., Sebastiania 
brasiliensis Spreng. e Sebastiania commersoniana (Baill.) L. B. Sm. \& Downs, dentre outras. Vogel (2005) salienta que no local existem indícios de que a área já tenha sido explorada com cultivo agrícola (cepas queimadas e cepas ramificadas).

\section{Metodologia de coleta}

Foram demarcadas seis parcelas de formato retangular, medindo 25,0 m x 17,0 m cada, alocadas no interior da floresta, de forma sistemática, conforme especificações de Péllico Netto \& Brena (1997). Em cada uma das parcelas, foram instalados cinco coletores, totalizando 30 coletores em toda a área experimental, constituídos por uma moldura de ferro de forma circular, com $50 \mathrm{~cm}$ de diâmetro, fixados a um metro de distância do solo.

Mensalmente, entre janeiro de 2006 e dezembro de 2007 , foi realizada a coleta do material vegetal depositado nos coletores. Em laboratório, todo o material foi separado nas frações folhas, galhos finos (diâmetro $<0,5 \mathrm{~cm}$ ) e miscelânea (flores, frutos, sementes e restos vegetais não identificáveis). Além disso, as folhas coletadas foram separadas, conforme as espécies com maior índice de valor de importância (IVI), com base no estudo de Longhi \& Greff (2006), e de fácil identificação, como a espécie Angicovermelho (Fabaceae, Parapiptadenia rigida (Benth.) Brenan), com IVI de 24,4; Aroeira (Anarcadiaceae, Lithraea molleoides (Vell.) Engl.), com IVI de 8,4; Camboatá-branco (Sapindaceae, Matayba elaeagnoides Radlk.), com IVI de 20,1; Camboatá-vermelho (Sapindaceae, Cupania vernalis Cambess.), com IVI de 9,8; Canela-guaicá (Lauraceae, Ocotea puberula (Rich.) Ness) com IVI de 8,9; Canela-lageana (Lauraceae, Ocotea pulchella (Nees \& Mart.) Mez), com IVI de 9,7; Canelapreta (Lauraceae, Nectandra megapotamica (Spreng.) Mez), com IVI de 7,5; grupo de família, para as demais espécies da família Fabaceae, e as demais foram classificadas como "outras".

Após esse procedimento de fracionamento e separação, as amostras foram secas, em estufa de circulação de ar, a $70^{\circ} \mathrm{C}$, pesadas e moídas em moinho tipo Willey, com peneira de 30 mesh, para posterior determinação dos teo- res de nutrientes, seguindo a metodologia descrita por Tedesco et al. (1995). O nitrogênio foi determinado pelo método Kjeldahl, após digestão sulfúrica, e, o B, por digestão seca. Após digestão nítrica-perclórica, foram determinados, o fósforo, por espectrofotometria; o potássio, por fotometria de chama; o enxofre, por turbidimetria e o cálcio, magnésio, cobre, ferro, manganês e zinco, por espectrometria de absorção atômica.

A partir do produto da massa seca de serapilheira, depositada nos coletores e dos teores de nutrientes nela contidos, pode-se estimar a transferência de nutrientes ao piso florestal, em relação a cada espécie estudada e para o total da Floresta Estacional Decidual. A análise estatística foi realizada, considerando-se delineamento inteiramente casualizado, em que a concentração de nutrientes na fração folhas de cada espécie, do total das espécies não identificadas e das frações galhos finos e miscelânea foram consideradas tratamentos e, os meses, as repetições. A comparação de médias foi realizada com o auxílio do programa estatístico ASSISTAT 7.6 beta (Silva, 2012), a 5\% de probabilidade. Para a comparação de médias, utilizou-se o teste Scott-Knott.

\section{RESULTADOS E DISCUSSÃO}

Verifica-se, na Tabela 2, a concentração média de nutrientes nas folhas da serapilheira de algumas espécies da Floresta Estacional Decidual, além dos galhos finos e miscelânea. Dentre as espécies identificadas, a espécie Parapiptadenia rigida, apresentou a maior concentração de nitrogênio na serapilheira foliar, o que é explicado, em parte, por ser uma leguminosa, com associações simbióticas com bactérias fixadoras de $\mathrm{N}_{2}$ atmosférico. A espécie Matayba elaeagnoides apresentou a maior concentração de potássio e a serapilheira foliar formada pelas espécies não identificadas da família Fabaceae, a concentração de manganês. A espécie Nectandra megapotamica apresentou maior concentração de $\mathrm{Zn}$.

Verifica-se, portanto, a existência de diferenças na concentração de nutrientes entre as espécies. Segundo Vitousek \& Sanford (1986), Boeger et al. (2005) e Barlow

Tabela 1. Atributos químicos do solo sob Floresta Estacional Decidual, Itaara, RS

\begin{tabular}{|c|c|c|c|c|c|c|c|c|c|c|}
\hline \multirow{2}{*}{ Prof. (cm) } & Arg. & M.O. & \multirow{2}{*}{ pH $\mathrm{H}_{2} \mathrm{O}$} & CTC $_{\text {eft }}$ & Al & $\mathrm{Ca}$ & Mg & $\mathbf{H}+\mathbf{A l}$ & \multicolumn{2}{|c|}{ Sat. (\%) } \\
\hline & \multicolumn{2}{|c|}{$\mathrm{g} \mathrm{kg}^{-1}$} & & \multicolumn{5}{|c|}{$\mathrm{cmol}_{\mathrm{c}} \mathrm{dm}^{-3}$} & Bases & $\mathrm{Al}$ \\
\hline $0-10$ & 135 & 51 & 5,5 & 7,1 & 0,0 & 4,8 & 2,0 & 4,6 & 59,0 & 0,0 \\
\hline \multirow[t]{2}{*}{$10-20$} & 183 & 31 & 5,5 & 7,0 & 0,2 & 4,7 & 2,0 & 5,2 & 54,7 & 2,3 \\
\hline & $\mathbf{K}$ & $\mathbf{P}$ & Zn & $\mathrm{Cu}$ & $\mathbf{S}$ & B & $\mathrm{Fe}$ & Mn & & \\
\hline \multicolumn{11}{|c|}{$\mathrm{mg} \mathrm{dm}{ }^{-3}$} \\
\hline $0-10$ & 143,0 & 3,6 & 4,3 & 0,1 & 13,5 & 0,7 & 9,3 & 73,6 & & \\
\hline $10-20$ & 50,7 & 2,2 & 1,1 & 0,2 & 11,3 & 0,7 & 16,3 & 42,7 & & \\
\hline
\end{tabular}

Fonte: Vogel (2005) 


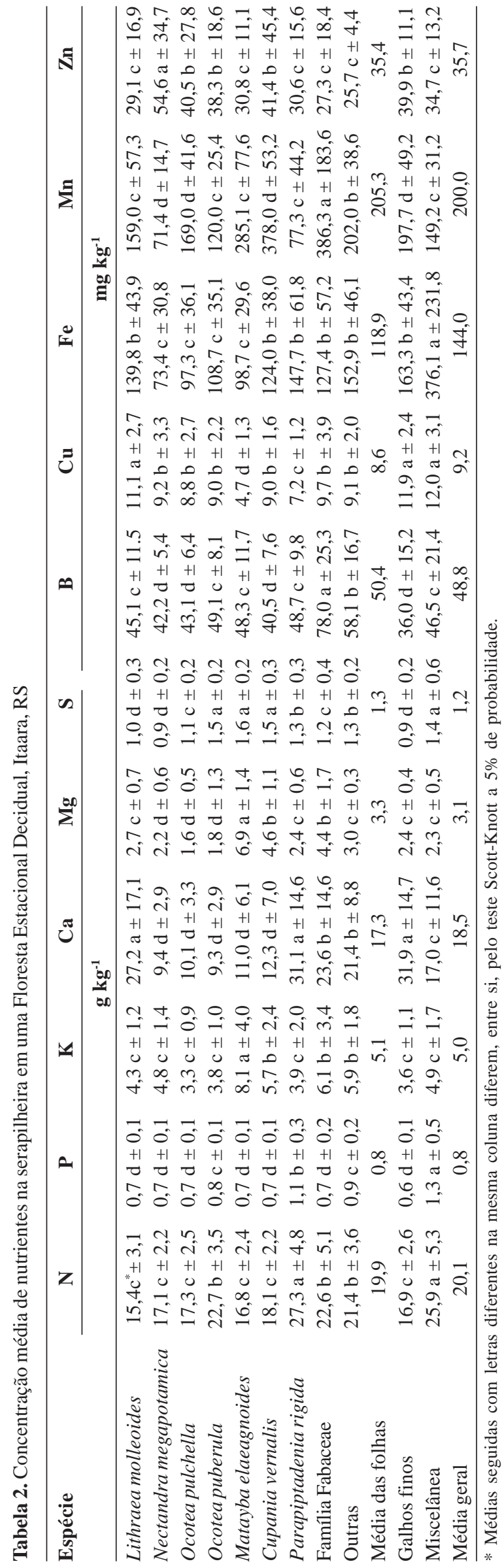

et al. (2007), essas diferenças podem ser atribuídas ao estádio sucessional da floresta e às características de cada espécie, como capacidade de absorção, translocação e utilização dos nutrientes. De forma geral, a fração miscelânea apresentou maior concentração de nitrogênio (não diferindo da serapilheira foliar de Parapiptadenia rigida), fósforo, enxofre (não diferindo de Ocotea puberula), cobre (não diferindo de Lithraea molleoides e da fração galhos finos) e de manganês. $\mathrm{O}$ elemento $\mathrm{Cu}$ apresentouse mais concentrado nos galhos e na serapilheira foliar da espécie Parapiptadenia rigida.

A razão de a miscelânea possuir maiores concentrações de alguns elementos, em relação às outras frações, é ser composta, em grande parte, de estruturas reprodutivas. Viera \& Schumacher (2010) observaram, em plantio de acácia-negra (Acacia mearnsii De Wild.) que, principalmente a concentração de $\mathrm{P}$ foi superior no material reprodutivo, em relação à encontrada na fração folhas. A elevada concentração de fósforo nas flores e nos frutos é explicada por ter esse elemento a função de estimular o crescimento, acelerar a maturação e ajudar a formação das sementes, a respiração e a absorção iônica de outros elementos (Ferri, 1985).

As frações folhas e miscelânea apresentaram a seguinte magnitude de concentração de macronutrientes: $\mathrm{N}>\mathrm{Ca}>$ $\mathrm{K}>\mathrm{Mg}>\mathrm{S}>\mathrm{Pe}$, para os micronutrientes, $\mathrm{Mn}>\mathrm{Fe}>\mathrm{B}>$ $\mathrm{Zn}>\mathrm{Cu}$. A fração galhos finos apresentou magnitudes similares às das outras frações, com exceção de para o $\mathrm{Ca}$ e Zn, que foram superiores ao $\mathrm{N}$ e $\mathrm{B}$, respectivamente. A maior concentração de $\mathrm{Ca}$ nos galhos decorre de esse nutriente ser considerado como imóvel, com função estrutural, fazendo parte da parede celular e presente, principalmente, em estruturas lignificadas (Ferri, 1985). Boeger et al. (2005) encontraram a mesma magnitude de concentração de macronutrientes, em relação a este estudo, em folhas maduras, para os estádios intermediário e avançado de sucessão de uma floresta Ombrófila Densa.

Observa-se, nas Tabelas 3 e 4, que grandes quantidades de nutrientes são transferidas por meio da deposição de serapilheira, demonstrando a importância dessa deposição para a manutenção do equilíbrio nutricional do ecossistema florestal. A contínua ciclagem de nutrientes (no sistema solo-planta-solo), em ecossistemas florestais estabelecidos em solos rasos, como o verificado neste estudo (em torno de $35 \mathrm{~cm}$ de profundidade), em que a ocupação radicular restringe-se a uma pequena camada do solo, é fundamental para a manutenção do equilíbrio nutricional do sistema. Se esta camada não for ciclada, nutricional e continuamente, seja por via de deposição de serapilheira, de precipitação úmida ou seca, de intemperização de rochas, de decomposição de árvores e de animais mortos, dentre outros, poderão ocorrer perdas significativas no ecossistema florestal (Pritchett, 1979). 
Dentre as espécies estudadas, em geral as folhas da espécie Parapiptadenia rigida contribuíram com os maiores aportes de nutrientes. Isso indica que essa espécie pode ser considerada uma das mais importantes dessa floresta, em relação à ciclagem de nutrientes. As três espécies com maiores quantidades de nutrientes transferidos ao solo, por via das folhas das espécies identificadas (Parapiptadenia rigida, Ocotea pulchella e Matayba elaeagnoides), juntas correspondem a 31,2\% do Zn; 30,9\% do N; 30,8\% do B; 30,4\% do S; 30,0\% do Ca; 29,4\% do $\mathrm{Mg} ; 28,9 \%$ do $\mathrm{P} ; 26,0 \%$ do $\mathrm{K} ; 23,1 \%$ do $\mathrm{Cu} ; 22,6 \%$ do $\mathrm{Mn}$ e $21,2 \%$ do Fe, em relação ao total de nutrientes contidos na serapilheira. Menor contribuição foi observada para as espécies Nectandra megapotamica, Ocotea puberula e Cupania vernalis, enquanto as demais apresentaram valores intermediários.
A fração folhas, em virtude da predominância de sua biomassa, contribui, em maior escala, para a ciclagem de nutrientes, sendo que sua participação relativa, no retorno de nutrientes, variou de 48,8\%, para o ferro, até $67,6 \%$, para o magnésio, seguida pela miscelânea, cuja participação relativa variou $13,2 \%$, para o cálcio, até $36,5 \%$, para o ferro, e por galhos finos, cujas variações foram de 11,4\%, para o enxofre, até $26,6 \%$, para o cálcio. A predominância da biomassa da fração folhas em ecossistemas naturais foi verificada por Toledo \& Pereira (2004), em florestas secundárias de Mata Atlântica; por Backes et al. (2005), em Floresta Ombrófila Mista; por Villela et al. (2006) e Pereira et al. (2008), em Mata Atlântica.

Segundo Olson (1963), Mason (1980), Haag (1985) e Cunha (1997), no processo de decomposição, o material foliar é decomposto mais rapidamente do que as demais

Tabela 3. Deposição média anual de serapilheira e macronutrientes das frações de serapilheira em uma Floresta Estacional Decidual, Itaara, RS

\begin{tabular}{|c|c|c|c|c|c|c|c|}
\hline \multirow{2}{*}{ Espécies } & Biomass & $\mathbf{N}$ & $\mathbf{P}$ & $\mathbf{K}$ & $\mathbf{C a}$ & Mg & $\mathbf{S}$ \\
\hline & \multicolumn{7}{|c|}{$\mathrm{kg} \mathrm{ha}^{-1} \mathrm{ano}^{-1}$} \\
\hline Lithraea molleoides & 1448,1 & $2,2^{(2,8 / 1,8) / *}$ & $0,1^{(3,3 / 1,9)}$ & $0,7^{(3,7 / 2,5)}$ & $4,2^{(5,3 / 3,2)}$ & $0,4^{(4,0 / 2,7)}$ & $0,2^{(3,1 / 2,1)}$ \\
\hline Nectandra megapotamica & 139,5 & $2,1^{(2,7 / 1,7)}$ & $0,1^{(3,3 / 1,9)}$ & $0,7^{(3,8 / 2,5)}$ & $1,4^{(1,8 / 1,1)}$ & $0,3^{(2,9 / 2,0)}$ & $0,1^{(2,9 / 2,0)}$ \\
\hline Ocotea pulchella & 436,2 & $7,2^{(9,2 / 5,8)}$ & $0,3^{(9,5 / 5,7)}$ & $1,5^{(8,3 / 5,5)}$ & $4,3^{(5,4 / 3,3)}$ & $0,7^{(6,4 / 4,4)}$ & $0,5^{(9,4 / 6,3)}$ \\
\hline Ocotea puberula & 197,9 & $4,3^{(5,5 / 3,5)}$ & $0,2^{(5,2 / 3,1)}$ & $0,7^{(4,2 / 2,8)}$ & $2,0^{(2,6 / 1,5)}$ & $0,4^{(3,3 / 2,2)}$ & $0,3^{(6,7 / 4,5)}$ \\
\hline Matayba elaeagnoides & 287,5 & $4,8^{(6,1 / 3,9)}$ & $0,2^{(6,2 / 3,7)}$ & $2,2^{(12,6 / 8,4)}$ & $2,8^{(3,5 / 2,1)}$ & $1,9^{(17,5 / 11,9)}$ & $0,5^{(9,8 / 6,6)}$ \\
\hline Cupania vernalis & 124,0 & $2,2^{(2,9 / 1,8)}$ & $0,1^{(2,9 / 1,8)}$ & $0,8^{(4,5 / 3,0)}$ & $1,5^{(1,8 / 1,1)}$ & $0,6^{(5,3 / 3,6)}$ & $0,2^{(4,0 / 2,7)}$ \\
\hline Parapiptadenia rigida & $1.000,0$ & $26,1^{(33,6 / 21,2)}$ & $1,0^{(32,7 / 19,5)}$ & $3,2^{(18,4 / 12,1)}$ & $32,4^{(40,9 / 24,6)}$ & $2,1^{(19,4 / 13,1)}$ & $1,3^{(26,2 / 17,5)}$ \\
\hline Família Fabaceae & 106,6 & $2,2^{(2,9 / 1,8)}$ & $0,1^{(2,6 / 1,6)}$ & $0,6^{(3,1 / 2,1)}$ & $3,4^{(4,3 / 2,6)}$ & $0,5^{(5,0 / 3,4)}$ & $0,1^{(2,7 / 11,8)}$ \\
\hline Outras & $1.260,0$ & $26,7^{(34,3 / 21,7)}$ & $1,1^{(34,3 / 20,5)}$ & $7,2^{(41,3 / 27,4)}$ & $27,2^{(34,3 / 20,7)}$ & $3,8^{(36,0 / 24,3)}$ & $1,7^{(35,1 / 23,6)}$ \\
\hline Folhas** & $3.699,8$ & $77,8^{(100,0 / 63,2)}$ & $3,1^{(100,0 / 59,6)}$ & $17,5^{(100,0 / 66,2)}$ & $79,2^{(100,0 / 60,2)}$ & $10,6^{(100,0 / 67,6)}$ & $4,8^{(100,0 / 67,0)}$ \\
\hline Galhos finos & $1.002,7$ & $15,7^{(12,7)}$ & $0,6^{(11,7)}$ & $3,4^{(12,9)}$ & $35,0^{(26,6)}$ & $2,4^{(15,5)}$ & $0,8^{(11,4)}$ \\
\hline Miscelânea & $1.148,4$ & $29,6^{(24,1)}$ & $1,5^{(28,7)}$ & $5,5^{(20,9)}$ & $17,4^{(13,2)}$ & $2,6^{(16,8)}$ & $1,6^{(21,7)}$ \\
\hline Total & $5.850,9$ & $123,2^{(100,0)}$ & $5,1^{(100,0)}$ & $26,4^{(100,0)}$ & $131,6^{(100,0)}$ & $15,6^{(100,0)}$ & $7,1^{(100,0)}$ \\
\hline
\end{tabular}

* Valores entre parênteses e em sobrescrito, referem-se ao percentual de cada espécie em relação ao total de cada nutriente na fração folhas e para o total na serapilheira. $* *$ Folhas $=$ Total da serapilheira foliar.

Tabela 4. Deposição média anual de micronutrientes das frações de serapilheira em uma Floresta Estacional Decidual, Itaara, RS

\begin{tabular}{|c|c|c|c|c|c|}
\hline \multirow{2}{*}{ Espécies } & B & $\mathrm{Cu}$ & $\mathbf{F e}$ & Mn & $\mathbf{Z n}$ \\
\hline & \multicolumn{5}{|c|}{$\mathrm{g} \mathrm{ha}^{-1}$ ano $^{-1}$} \\
\hline Lithraea molleoides & $6,6^{(3,3 / 2,3) / 2}$ & $1,6^{(5,2 / 2,8)}$ & $21,9^{(4,2 / 2,1)}$ & $23,0^{(3,6 / 2,3)}$ & $3,9^{(3,2 / 2,0)}$ \\
\hline Nectandra megapotamica & $5,8^{(2,9 / 2,1)}$ & $1,2^{(3,8 / 2,1)}$ & $12,4^{(2,4 / 1,2)}$ & $10,5^{(1,6 / 1,0)}$ & $7,7^{(6,2 / 3,9)}$ \\
\hline Ocotea pulchella & $19,1^{(9,7 / 6,8)}$ & $4,1^{(13,4 / 7,4)}$ & $48,0^{(9,3 / 4,5)}$ & $75,0^{(11,6 / 7,5)}$ & $21,6^{(17,4 / 11,0)}$ \\
\hline Ocotea puberula & $9,7^{(4,9 / 3,5)}$ & $1,8^{(5,7 / 3,2)}$ & $24,8^{(4,8 / 2,4)}$ & $25,7^{(4,0 / 2,6)}$ & $7,4^{(6,0 / 3,8)}$ \\
\hline Matayba elaeagnoides & $13,2^{(6,7 / 4,7)}$ & $1,3^{(4,4 / 2,4)}$ & $31,2^{(6,1 / 3,0)}$ & $77,4^{(11,9 / 7,7)}$ & $10,1^{(8,2 / 5,1)}$ \\
\hline Cupania vernalis & $4,5^{(2,3 / 1,6)}$ & $1,1^{(3,7 / 2,0)}$ & $16,4^{(3,2 / 1,6)}$ & $47,4^{(7,3 / 4,7)}$ & $7,8^{(6,3 / 4,0)}$ \\
\hline Parapiptadenia rigida & $54,1^{(27,4 / 19,3)}$ & $7,4^{(24,2 / 13,3)}$ & $144,2^{(28,0 / 13,7)}$ & $74,5^{(11,5 / 7,4)}$ & $29,8^{(24,0 / 15,1)}$ \\
\hline Família Fabaceae & $9,4^{(4,7 / 3,3)}$ & $1,2^{(3,8 / 2,1)}$ & $16,2^{(3,2 / 1,5)}$ & $52,4^{(8,1 / 5,2)}$ & $4,0^{(3,2 / 2,0)}$ \\
\hline Outras & $75,2^{(38,1 / 26,8)}$ & $11,0^{(35,9 / 19,7)}$ & $200,0^{(38,8 / 19,0)}$ & $261,7^{(40,4 / 26,10)}$ & $32,0^{(25,7 / 16,2)}$ \\
\hline Folhas ${ }^{13}$ & $197,4^{(100,0 / 70,4)}$ & $30,7(100,0 / 55,0)$ & $515,1^{(100,0 / 48,8)}$ & $647,7(100,0 / 64,6)$ & $124,3^{(100,0 / 63,1)}$ \\
\hline Galhos finos & $34,4^{(12,3)}$ & $11,5^{(20,6)}$ & $154,8^{(14,7)}$ & $193,0^{(19,2)}$ & $37,4^{(19,0)}$ \\
\hline Miscelânea & $48,8^{(17,4)}$ & $13,6^{(24,4)}$ & $385,5^{(36,5)}$ & $162,3^{(16,2)}$ & $35,3^{(17,9)}$ \\
\hline Total & $280,5^{(100,0)}$ & $55,8^{(100,0)}$ & $1.055,4^{(100,0)}$ & $1.002,9^{(100,0)}$ & $197,0^{(100,0)}$ \\
\hline
\end{tabular}

* Valores entre parênteses e em sobrescrito, referem-se ao percentual de cada espécie em relação ao total de cada nutriente na fração folhas e para o total na serapilheira. $* *$ Folhas $=$ Total da serapilheira foliar. 
frações da serapilheira, tornando maior quantidade de nutrientes disponíveis no solo em menor tempo.

A magnitude média de aporte de nutrientes por via da serapilheira foi da seguinte ordem: $\mathrm{Ca}>\mathrm{N}>\mathrm{K}>\mathrm{Mg}>\mathrm{S}>$ $\mathrm{P}$, para os macronutrientes, e Fe $>\mathrm{Mn}>\mathrm{B}>\mathrm{Zn}>\mathrm{Cu}$, para os micronutrientes. Essa sequência de aporte de nutrientes pela serapilheira corrobora o resultado encontrado em outros estudos (Cunha et al., 1993; Cunha, 1997; GamaRodrigues \& Barros, 2002; Caldeira et al., 2008) em florestas nativas.

\section{CONCLUSÕES}

A maior deposição de nutrientes ocorreu por meio da fração folhas, seguida pela dos galhos finos e da miscelânea. Dentre as espécies identificadas e avaliadas, a espécie Parapiptadenia rigida apresentou a maior transferência de nutrientes ao solo, com exceção do Mn, que foi mais transferido pela espécie Matayba elaeagnoides, que, juntamente com a espécie Ocotea pulchella, são as principais espécies em aporte de nutrientes na floresta Estacional Decidual avaliada.

\section{AGRADECIMENTOS}

Os autores agradecem à Brigada Militar do Estado do Rio Grande do Sul, por ceder a área em que foi realizado o presente estudo, localizada no Centro de Estudos e Treinamento, Reprodução Animal e Proteção Ambiental (CETRAPA) no município de Itaara-RS.

\section{REFERÊNCIAS}

Backes A, Prates FL \& Viola MG (2005) Produção de serapilheira em Floresta Ombrófila Mista, em São Francisco de Paula, Rio Grande do Sul, Brasil. Acta Botânica Brasílica, 19:155-160.

Barlow J, Gardner TA, Ferreira LV \& Peres CA (2007) Litter fall and decomposition in primary, secondary and plantation forests in the Brazilian Amazon. Forest Ecology and Management, 247:91-97.

Boeger MRT, Wisniewski C \& Reissmann CB (2005) Nutrientes foliares de espécies arbóreas de três estádios sucessionais de floresta ombrófila densa no sul do Brasil. Acta Botânica Brasílica, 19:167-181.

Caldeira MVW, Vitorino MD, Schaadt SS, Moraes E \& Balbinot R (2008) Quantificação de serapilheira e de nutrientes em uma Floresta Ombrófila Densa. Revista do Setor de Ciências Agrárias, 29:53-68

Cunha GC (1997) Aspectos da ciclagem de nutrientes em diferentes fases sucessionais de uma Floresta Estacional do Rio Grande do Sul. Dissertação de Mestrado. Escola Superior de Agricultura "Luiz de Queiroz", Piracicaba. 86p.

Cunha GC, Grendene LA, Durlo MA \& Bressan DA (1993) Dinâmica nutricional em floresta estacional decidual com ênfase aos minerais provenientes da deposição da serapilheira. Ciência Florestal, 3:35-64.

Ferri MG (1985) Fisiologia vegetal 1. $2^{\text {a }}$ ed. São Paulo, EPU. $362 \mathrm{p}$.
Gama-Rodrigues AC \& Barros NF (2002) Ciclagem de nutrientes em floresta natural e em plantios de eucalipto e de dandá no Sudoeste da Bahia, Brasil. Revista Árvore, 26:193-207.

Golley FB (1983) Nutrient cycling and nutrient conservation. In: Tropical forest ecosystems: structure and function. Amsterdam, Elsevier. p.137-156.

Haag HP (1985) Ciclagem de nutrientes em florestas tropicais. Campinas, Fundação Cargill. 144p.

Herrera R, Jordan CF, Medina E \& Klinge H (1981) How human activities disturb the nutrient cycles of a tropical rain forest Amazonia. Ambio, 10:109-114.

Jordan CF (1985) Ciclagem de nutrientes e silvicultura de plantações na Bacia Amazônica. In: Reunião Brasileira de Fertilidade do Solo, Ilhéus. Anais, Sociedade Brasileira de Ciência do Solo. p. 187-202.

Klein RM (1983) Aspectos fitofisionômicos da Floresta Estacional da Fralda da Serra Geral (RS). In: Congresso Nacional de Botânica, Porto Alegre. Anais, Congresso Nacional de Botânica. p.73-110.

Koehler CW, Reissmann CB \& Koehler HS (1987) Deposição de resíduos orgânicos (serapilheira) e nutrientes em plantio de Araucaria angustifolia em função do sítio. Revista do Setor de Ciências Agrárias, 9:89-94.

Longhi SJ, Nascimento ART, Fleig FD, Della-Flora JB, Freitas RA \& Charão LW (1999) Composição florística e estrutura da comunidade arbórea de um fragmento florestal no município de Santa Maria-Brasil. Ciência Florestal, 9:115-133.

Longhi SJ \& Greff LTB (2006) Distribuição de espécies arbóreas em relação a parâmetros ambientais em uma Floresta Estacional Decidual no município de Itaara, RS. Relatório de Iniciação Científica (CNPq/Pibic). Universidade Federal de Santa Maria, Santa Maria. 16p.

Mason CF (1980) Decomposição. São Paulo, EPU/EDUSP. 63p. (Temas de Biologia, 18).

Moreno JA (1961) Clima do Rio Grande de Sul. $1^{\mathrm{a}}$ ed. Porto Alegre, Secretaria da Agricultura. 83p.

Neves EJM, Martins EG \& Reissmann CB (2001) Deposição de serapilheira e de nutrientes de duas espécies da Amazônia. Boletim de Pesquisa Florestal, 43:47-60.

Olson JS (1963) Energy storage and the balance of producers and decomposers in ecological systems. Ecology, 44:322-330.

Péllico Netto S \& Brena DA (1997) Inventário Florestal. Santa Maria, UFSM/CEPEF. 315p.

Pereira MG, Menezes LFT \& Schultz N (2008) Aporte e decomposição da serapilheira na Floresta Atlântica, Ilha da Marambaia, Mangaratiba, RJ. Ciência Florestal, 18:443-454.

Poggiani F \& Schumacher MV (2004) Nutrient cycling in native forests. In: Gonçalves JLM \& Benedetti V (Eds.) Forest nutrition and fertilization. $2^{\mathrm{a}}$ ed. Piracicaba, IPEF. p.285-306.

Pritchett WL (1979) Properties and management of forest soils. New York, John Wiley. 500p.

Secretaria Estadual do Meio Ambiente (2002) Inventário Florestal Contínuo do Rio Grande do Sul. Porto Alegre, Fatec/Sema. Disponível em: <www.ufsm.br/ifcrs>. Acessado em: 15 de outubro de 2012.

Silva F de AS (2012) ASSISTAT - Statistical Assistance. versão 7.6 beta. Campina Grande, Universidade Federal de Campina Grande. Disponível em: <http://www.assistat.com/indexi.html>. Acessado em: 15 de dezembro de 2009.

Streck EV, Kämpf N, Dalmolin RSD, Klamt E, Nascimento PC, Schneider P, Giasson E \& Spinelli Pinto LF (2008) Solos do Rio Grande do Sul. $2^{\mathrm{a}}$ ed. Porto Alegre, EMATER/RS. 222p.

Rev. Ceres, Viçosa, v. 59, n.6, p. 765-771, nov/dez, 2012 
Tedesco MJ, Gianello C, Bissani CA, Bohnen H \& Volkweiss SJ (1995) Análise de solo, plantas e outros materiais. Porto Alegre, UFRGS. 174p. (Boletim Técnico, 5).

Toledo LO \& Pereira MG (2004) Dinâmica da deposição de serapilheira em florestas secundárias do município de Pinheiral, RJ. Floresta e Ambiente, 11:39-46.

Viera M, Caldato SL, Rosa SF, Kanieski MR, Araldi DB, Santos SR \& Schumacher MV (2010) Nutrientes na serapilheira em um fragmento de floresta estacional decidual, Itaara, RS. Ciência Florestal, 20:611-619.

Viera M \& Schumacher MV (2010) Deposição de serapilheira e de macronutrientes em um povoamento de acácia-negra (Acacia mearnsii De Wild.) no Rio Grande do Sul. Ciência Florestal, 20:225-233.
Villela DM, Nascimento MT, Aragão LE \& Gama DM (2006) Effect of selective logging on forest structure and nutrient cycling in a seasonally dry Brazilian Atlantic forest. Journal of Biogeography, 33:506-516.

Vital ART, Guerrini IA, Franken WK \& Fonseca RCB (2004) Produção de serapilheira e ciclagem de nutrientes de uma floresta estacional semidecidual em zona ripária. Revista Árvore, 28:793-800

Vitousek PM \& Sanford RL (1986) Nutrient cycling in moist tropical forest. Annual Review Systems, 17:137-167.

Vogel HM (2005) Quantificação da biomassa e nutrientes em uma floresta Estacional Decidual em Itaara-RS, Brasil. Tese de Doutorado. Universidade Federal de Santa Maria, Santa Maria. 94p. 